\title{
XLVIII. A new form of constant-temperature bath
}

\author{
W.W.J. Nicol M.A. B.Sc. F.R.S.E.
}

To cite this article: W.W.J. Nicol M.A. B.Sc. F.R.S.E. (1883) XLVIII. A new form of constant-temperature bath, Philosophical Magazine Series 5, 15:95, 339-341, DOI: $\underline{10.1080 / 14786448308627359}$

To link to this article: http://dx.doi.org/10.1080/14786448308627359

曲 Published online: 28 Apr 2009.

Submit your article to this journal

Џ Article views: 2

Q View related articles $\sqsubset$ 
were on occasions deceived by the presence of a concealed aurora, and thus the zodiacal light and the aurora spectra were at first confounded. Seeing, also, how up to the present time we have quite failed to produce in our laboratories any form of electric discharge which by its spectrum can fairly be pronounced as of an auroral character, it would seem desirable to wait the result of later and fuller particulars from the learned Professor before passing a definite judgment on the matter. We do not at present hear of any comparisons of the "artificial" aurora-spectrum with other spectra which will explain its true and so long hidden character; though doubtless, if we can succeed in establishing an aurora "en permanence," good results may reasonably be expected to follow, one principal cause of failure in explanation of the Aurora mystery being the infrequency of the opportunities afforded of examining its spectrum and comparing it directly with others.

Guildown, April 6, 1883.

XLVIII. A new Form of Constant-Temperature Bath. By W. W. J. Nicol, M.A., B.Sc., F.R.S.E., Lecturer on Chemistry, Mason College, Birmingham*.

THE want of a simple and, at the same time, reliable con1 stant-temperature bath has been felt by all who have made specific-gravity determinations. The following apparatus, which has been found thoroughly efficient, was devised by me during the course of my experiments on the specific gravity of salt-solutions, the results of which have been recently published $\dagger$.

The apparatus consists of three parts-the bath, the heating arrangement, and the thermostat. The bath is of copper, measuring 200 millim. in length, 200 millim. in depth, and 90 millim. in width-a size I found most convenient for use with the Sprengel tubes described in the 'Chemical News' (February 1883). Near one ond is soldered a wide brass tube (C, fig 1 ) with a slot down one side: this is intended to receive the thermostat and thermometer. The water in the bath is agitated by means of a current of air supplied by a Fletcher's blower. The air escapes from a perforated tube lying on the bottom of the bath.

* Communicated by the Author.

† Proceedings Roy. Soc. Edin. 1881-82 ; Ber. deut. Chem. Ges. 1882, p. 1931 ; Phil. Mag. 1883, February; Chem. Soc. Journ. 1883, March. 
The heating arrangement is as follows :-At the end of the bath, where the tube $\mathrm{C}$ is placed, two holes are made close to

Fig. 1.

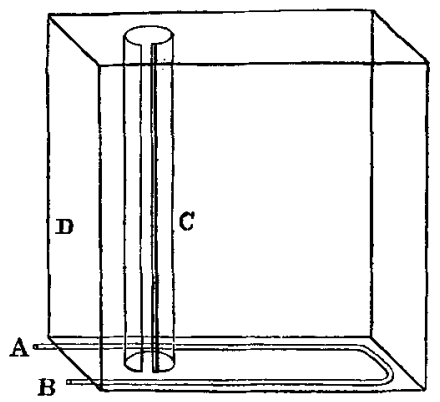

Fig. 2.

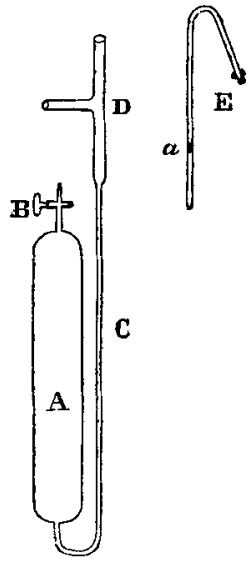

the bottom ; through these passes the copper tube A, B. The end $A$ is coiled into a spiral of four or five turns about an inch in diameter (not shown in the figure). The bath having been placed on a stand in the required position, with the end $D$ away from the experimenter, the copper spiral is surrounded by a roll of tin-plate, and the upper end of the tube connected with the water-supply, which must not be direct from the main. The end $B$ is then furnished with a tube to convey away the water. Below the spiral is placed a Bunsen, the supply of gas to which is governed by the thermostat.

The thermostat is shown in fig. 2. The reservoir $A$ is made of thin glass tube, 30 millim. wide and abont 170 millim. long; to the upper end is joined a small stopcock B ; to the lower end the tube $\mathrm{C}$ (4 millim. internal diameter) is connected (the length of $\mathrm{C}$ is about 230 millim.) ; to the upper end of $\mathrm{C}$ is joined a $\mathrm{T}$-piece $\mathrm{D}$ made of a tube 6 millim. in internal diameter and 80 millim. long. Finally a thin tube E, 2.5 millim. in external diameter, is bent in the form shown-the longer limb slightly drawn out, and a small bole made at $a$. The reservoir $\mathrm{A}$ and tube $\mathrm{C}$ are then filled with benzoline or paraffin oil, according to the temperature required for the bath; and a quantity of mercury is introduced sufficient to occupy the whole of the tube $\mathrm{C}$ and a small part of $\mathrm{A}$ when the desired temperature is attained. The tube $\mathbb{E}$ is then inserted into $\mathrm{D}$ and fastened by a small cork, in such a way that the end is just below the point of juncture of $\mathrm{C}$ and $\mathrm{D}$. 
On the "Rotational Coefficients" of various Metals. 341

The thermostat is next placed in position in the tube $\mathrm{C}$ (fig. 1), the thermometer placed beside it, and the bath filled up with water ; the aircurrent is then turned on, and the gassupply so arranged that it enters the thermostat by $\mathrm{E}$ and passes to the Bunsen by the side tube of $D$. A very slow stream of water is allowed to flow through the spiral, and the Bunsen is lighted. The stopcock B, at first closed, is opened from time to time, until, when the desired temperature is reached, the column of mercury in $C$ just touches the end of $\mathrm{E}$; the flame of the Bunsen is thus lowered, and cold water flows through the spiral cooling the bath. As the temperature of the bath falls, the mercury falls below the end of $\mathrm{E}$, and the water is heated before entering the bath; after a few oscillations of temperature a state of equilibrium is reached, in which the size of the flame is so adjusted to the quantity of water flowing through the spiral that the temperature of the bath remains constant.

I have found that the extreme variation of temperature does not exceed $0^{\circ} 05$ for a temperature of $20^{\circ} \mathrm{C}$., and that on lighting the gas in the morning the constant temperature was attained in less than an hour, and never varied from day to day.

XLIX. "Rotational Coefficients" of various Metals. By EDWIN H. HALL*.

THE experiments described below were made at the labo1 ratory of Harvard College during the summer of 1882; and most of the results obtained were given at the Montreal meeting of the American Association.

At the York meeting of the British Association, September 1881, I gave a list of certain metals with an approximate value of the "rotational coefficient" + for each, as determined by my experiments. This list was published in the Report of the Association. Several of these metals had, however, been examined in an extremely inaccurate manner, as was stated at the time, and the numbers assigned them were marked as doubtful. Thus a part of the list ran:-

$$
\begin{aligned}
& \text { Name of metal. } \begin{array}{c}
\text { Rotational coefficient, } \\
\text { arbitrary scale. }
\end{array} \\
& \text { Zinc . . . . + } 15 \text { ? } \\
& \text { Aluminium . . }-50 \text { ? } \\
& \text { Magnesium . . - }-50 \text { ? } \\
& \text { Copper . . . }-10 \text { ? } \\
& \text { Brass . . . . }-1 \cdot 3 \text { ? } \\
& \text { Lead . . . . . No effect discovered. }
\end{aligned}
$$

* From Silliman's American Journal for March 1883.

$\uparrow$ Phil. Mag. Sept. 1881, p. 162. 